\title{
UMA QUESTÃo CONTROVERSA: A Separação de Fato como elemento para concessão de pensão por morte no Regime Geral de Previdência Social e a Súmula 336 do Superior Tribunal de Justiça ${ }^{1}$
}

\author{
Larissa Nunes Cavalheiro ${ }^{2}$ \\ Luiz Aristeu dos Santos Filho ${ }^{3}$ \\ Fernando Hoffmam ${ }^{4}$ \\ Franciele da Silva Câmara ${ }^{5}$
}

\begin{abstract}
RESUMO: Nos casos de concessão da pensão por morte no Regime Geral da Previdência Social, quem pleiteia esse benefício às vezes encontra dificuldades legais. Um exemplo é o caso da separação de fato do cônjuge do segurado, uma vez que a Lei 8.213/91, dá ensejo a mais de uma interpretação para a concessão do benefício, oscilando entre dependência econômica presumida ou a comprovação da mesma. Com o advento da Súmula 336 do STJ, verifica-se outro momento em que aqueles que estão separados apenas de fato têm suprimida a possibilidade de recebimento da pensão por morte em momento futuro, e de certa forma, fere o Princípio da Igualdade. Diante da realidade, quando se refere à separação de fato não há uma clara abordagem, correndo-se o risco de preterir possíveis beneficiários. O presente trabalho analisa as divergências da falta de previsão legislativa, bem como os efeitos da citada súmula.
\end{abstract}

PALAVRAS-CHAVE: Pensão por morte. Separação de fato. Dependência. Necessidade.

\section{A CONTROVERSIAL ISSUE: The In Factum Separation as an element that} determines the possibility of concession of the pension on General Regimen of the Social Security and the Precedent 336 of the Superior Court of Justice

\begin{abstract}
In the case of concession of a pension by the beneficiary's death on General Regimen of the Social Security, the persons who plead this benefit have some difficulties, considering the lapses of the Act. A clear example is the situation of the In Factum Separation, once the Social Security Act indecisions gives rise to more than only one interpretation, hanging from the supposed economic dependence to its factual confirmation. The Precedent 336 from the Superior Court of Justice considers that this kind of separation could create the possibility of the recognition of the right for a pension what violates the Equity. About the question of pensions, there is no clear approach, in the case of In Factum Separation, what could create some risk to the constitutional and Human Rights. The purpose of this paper is the analysis of this question, and the effects of the Precedent 336.
\end{abstract}

KEYWORDS: Pension by death of the beneficiary. In Factum Separation. Dependence. Necessity.

\footnotetext{
1 Trabalho de pesquisa acadêmica em colaboração conjunta, desenvolvido pelo grupo por conta de atividades jurídicas envolvendo o tema.

2 Especializanda em Direito Público pela Escola Superior da Magistratura Federal e em Educação Ambiental pela Universidade Federal de Santa Maria; bacharel em Direito pelo Centro Universitário Franciscano. Advogada. E-mail: laranunes7@ hotmail.com.

${ }^{3}$ Mestrando em Ciências Sociais pela Universidade Federal de Santa Maria; bacharel em Administração, Ciências Sociais e licenciado em Sociologia pela Universidade Federal de Santa Maria. Bacharel em Direito pelo Centro Universitário Franciscano. Advogado. e-mail: luizaristeufilho@bol.com.br.

${ }^{4}$ Bacharel em Direito pelo Centro Universitário Franciscano. e-mail: ferdhoffa@yahoo.com.br.

${ }^{5}$ Especializanda em Gestão Pública Municipal pela Universidade Federal do Rio Grande do Sul; bacharel em Direito pelo Centro Universitário Franciscano. e-mail: fran_justitia@ hotmail.com.
} 


\section{INTRODUÇÃO}

A pensão por morte no Regime Geral da Previdência Social prevista no art. 74 da Lei 8.213/91 é um direito dos dependentes do de cujus quando da sua morte real ou presumida do beneficiário. Por meio de tal direito, é-lhes garantido uma prestação pecuniária. No entanto, para o exercício desse direito, é necessária a comprovação da dependência econômica.

Conforme o previsto no art. 16 da mesma Lei, presumem-se como sendo beneficiários: o cônjuge, a companheira, o companheiro e os filhos não emancipados, de qualquer condição, menores de 21 anos ou inválidos. Desse modo, acredita-se que o segurado era responsável pela subsistência desses, quando existentes, configurando assim a dependência econômica.

Põem, ao mesmo tempo em que regula todas essas circunstâncias, a Lei não prevê, até porque seria impossível, todas as situações/relações vivenciadas na sociedade. Sendo assim, surgem consideráveis divergências quanto às soluções dadas aos conflitos dos inúmeros e peculiares casos concretos que, surgem no Judiciário. Essa situação ocorre depois de esgotadas as vias administrativas do INSS, quando do requerimento da pensão por indivíduos que crêem ser beneficiários, cuja condição não está especificada no art. 16.

A realidade revela inúmeras separações apenas de fato e a referida Lei não demonstra com clareza a solução para o caso concreto. Diz-se isso, pois através de uma leitura atrelada à norma, percebe-se uma dupla consideração legal para a separação de fato. Primeiramente, a dependência econômica é presumida, levando em consideração que a sociedade conjugal não foi dissolvida juridicamente. Da leitura da Lei, surge um novo imperativo: a comprovação da dependência econômica daquele que requer o benefício, através do recebimento prévio de uma pensão alimentícia para ensejar o seu recebimento.

Não bastasse o aparecimento de novas questões sociais ainda sem claro amparo legal, veio a Súmula 336 do STJ. Por meio dela, amplia-se a margem de interpretações, trazendo à tona a questão da "necessidade econômica superveniente" ao dilema. A referida súmula fala em separação judicial em que se renuncia à pensão alimentícia.

Porém, no cotidiano é comum se verificar separações apenas de fato. É preciso fica claro que nesses casos, o cônjuge nem mesmo exerce esse direito. Em primeiro lugar, porque não ocorre uma separação judicial que enseje eventual pedido de divórcio. 
Em segundo lugar, também, por haver apenas a separação de corpos, o teor dessa separação, é suficiente, no momento em que a mesma ocorre, em vista de estabelecer o "cancelamento do vínculo" entre os que antes formavam um casal.

Frente a essas condições, pode-se avaliar que a Súmula 336 do STJ pode ser usada em benefício das separações de fato, nos quais nunca houve prestação alimentícia. Isso é possível, pois traz consigo a exigência da "necessidade econômica superveniente", sendo esta comprovada tanto por aquele que teve a separação judicial, como para a de fato. Desta forma estar-se-ia apenas obedecendo ao Princípio da Igualdade, visto que a súmula trata de uma situação prevista conjuntamente com a separação de fato, ambas elencadas no artigo 76, § $2^{\circ}$ da Lei 8.213/91.

Com isso, surge a questão: por que para a renúncia de alimentos na separação judicial é dada a "oportunidade" de se comprovar necessidade superveniente? E quanto à separação de fato, na qual o direito aos alimentos também não é exercido, não pode haver o mesmo entendimento? Principalmente considerando-se que, contrariamente, é exigida a comprovação de uma dependência econômica anterior nesses casos? Essa é uma dúvida essencial que precisa ser respondida.

Diante dessas controvérsias se faz importante a análise da adoção dos referidos fundamentos/entendimentos usados para a concessão da pensão por morte, avaliando qual a melhor maneira de atender o caso concreto da forma mais justa, diante das atuais

situações fáticas. É esse o escopo do presente trabalho, analisar a Lei pertinente a pensão por morte, assim como, ante o Princípio da Igualdade, abordar os diferentes fundamentos, para a questão. Principalmente aquele referente à necessidade econômica superveniente e à dependência econômica anterior, quando adotados para a concessão do benefício.

\section{SEPARAÇÃO DE FATO E DEPENDÊNCIA ECONÔMICA: PRESUNÇÃO OU COMPROVAÇÃO?}

Na situação atual da sociedade, os proventos e as pensões desempenham um papel essencial. É por meio deles que se determina a manutenção de padrões de consumo e, com isso, garante um processo de integração social de aposentados e pensionistas, como observa Christo (2009). A pensão por morte, de modo semelhante, destina-se a amparar aqueles que dependiam economicamente de um segurado do 
Regime Geral da Previdência Social que venha a falecer, tornando possível a integração econômica de seus dependentes em uma sociedade de consumo.

Os dependentes do segurado, delimitados pela lei como essenciais e obrigatórios, são elencados no inciso I do art. 16 da Lei 8213/91, a saber:

\begin{abstract}
Art. 16. São beneficiários do Regime Geral de Previdência Social, na condição de dependentes do segurado:

I - o cônjuge, a companheira, o companheiro e o filho não emancipado, de qualquer condição, menor de 21 (vinte e um) anos ou inválido; (BRASIL, 2009, p. 1489).
\end{abstract}

Como estabelece o artigo supra, as pessoas elencadas nessa categoria têm a sua dependência presumida. Desse modo, não há necessidade de qualquer comprovação de dependência, para que possa ser deferida a concessão do benefício a qualquer um deles. Basta tão-somente a comprovação de um vínculo legal ou genético.

Indo mais adiante na referida Lei, chegando ao artigo $76, \S 2^{\circ}$. Conforme esse artigo especifica, acerca da concessão da pensão por morte, percebe-se que:

Art. 76. A concessão da pensão por morte não será protelada pela falta de habilitação de outro possível dependente, e qualquer inscrição ou habilitação posterior que importe em exclusão ou inclusão de dependente só produzirá efeito a contar da data da inscrição ou habilitação.[...]

$\$ 2^{\circ}$. O cônjuge divorciado ou separado judicialmente ou de fato que recebia pensão de alimentos concorrerá em igualdade de condições com os dependentes referidos no inciso I do art. 16 desta Lei (BRASIL, 2009, p. 1498).

Por meio dele, verifica-se a clara adoção da comprovação da dependência econômica, no caso da Separação de Fato. E essa comprovação é feita através do recebimento de pensão alimentícia. Por meio desta condição, para que, o cônjuge separado judicialmente e o divorciado, assim como o separado de fato, concorram em igualdade de condições com aqueles dependentes referidos no artigo 16, inciso I da lei $8.213 / 91$.

Nota-se então que a referida Lei exige a anterior existência de assistência financeira, na forma de pensão alimentícia, para que se possa ensejar a concessão da pensão por morte para aqueles entre os quais não corre a presunção da dependência econômica. Sendo assim, concorrem com os previstos na primeira classe do inciso I, do artigo 16, ocorrendo o rateio em cotas iguais. Isso ocorre tendo-se em vista que esse é o conteúdo expresso do art. 77 da lei já referida, segundo o qual: “Art. 77. A pensão por 
morte, havendo mais de um pensionista, será rateada entre todos em partes iguais (BRASIL, 2009, p. 1498).”

Aqueles que possuem direito, quando pertencerem às classes inferiores, de acordo com o artigo $16, \S 1^{\circ}$, serão excluídos, na existência daqueles pertencentes às classes superiores. Até esse ponto não há dissensões, pois se dependentes durante a vida do segurado seja de forma presumida ou comprovada, porque deixariam de ser com a morte daquele?

Excluindo o caso dos filhos de qualquer idade, cessada sua condição de invalidez ou alcançados 21 anos, fatos que geram a perda do benefício, poucas são as condições que tem como efeito a perda deste. E isso fica evidente uma vez que se aqueles que possuíam laços de afinidade, seja um casamento ou mesmo uma união estável, não tornarem a estabelecer novo relacionamento válido, nos moldes do ordenamento jurídico, não terão seu benefício cancelado. O que pode criar situações de difícil resolução, considerando-se o tema e que mereceriam atenção do legislador ou do julgador, caso ocorram.

As divergências começam a surgir quando se pensa na separação de fato, sendo os referidos dispositivos até aqui elucidados suficientes para suscitarem dúvidas, assim como diferentes entendimentos nas decisões judiciais referentes à matéria. Nota-se, sobre o tema, em termos jurisprudenciais, houve decisões no sentido de que ante a separação de fato, pela natureza da decisão do casal, não se pode permitir o exercício da presunção da dependência econômica, em função da alteração do animus que mantinha os mantinha unidos. Assim, o julgador estabeleceu que:

PREVIDENCIÁRIO. PENSÃO POR MORTE. CÔNJUGE. SEPARAÇÃO FÁTICA. DEPENDÊNCIA ECONÔMICA. FALTA DE COMPROVAÇÃO. CONCESSÃO DO BENEFÍCIO SOMENTE AOS FILHOS MENORES.

1. A concessão do benefício de pensão por morte depende da ocorrência do evento morte, da demonstração da qualidade de segurado do de cujus e da condição de dependente de quem objetiva a pensão.

2. Ainda que o artigo 16 da Lei $n^{o} 8.213 / 91$ inclua o marido no rol de beneficiários do RGPS, tendo havido separação fática, a dependência não é mais presumida, devendo ser comprovada.

3. Ausente a comprovação de que o marido separado de fato dependia da segurada falecida, não lhe é devido o benefício de pensão por morte.

[...] (PARANÁ. 2009, s. p.)

Porém, em situação análoga, a regra utilizada foi a de que ante a separação de fato, entende-se que ainda assim há dependência econômica, em função da não- 
alteração da condição de oficial casamento ou união estável. Portanto, mesmo separados apenas de fato, não há alteração da dependência econômica, sendo necessário apenas comprovar a condição de cônjuge, vez que este, pela lógica da regra vigente se presume dependente. Assim, "Comprovada a condição de cônjuge do de cujus, a dependência econômica é presumida, nos termos do $\S 4^{\circ}$ artigo 16 da Lei 8.213/91. A separação de fato do casal, por si só, não afasta a presunção de dependência econômica" (SÃO PAULO, 2005, s. p.)

Fazendo uma breve leitura da Lei 8.213/91, a separação de fato enseja a manutenção da presunção de dependência, uma vez que, a sociedade conjugal original não foi dissolvida oficialmente. Em outros casos, porém, deverá ser comprovado o recebimento da pensão alimentícia, para que se possa dar ensejo ao futuro benefício da pensão por morte. Desse modo, a situação se complica em função da indeterminação da lei, que em momentos diversos, dá tratamentos distintos.

E, como efeito, essa situação pode ser prejudicial para o separado de fato, uma vez que essa é uma inconstância que deverá ser avaliada pelo julgador. E, como se viu, há casos em que se opta pela regra do caput art. 16, da Lei 8.213/91 e em outras pela regra do $\S 4^{\circ}$ do mesmo artigo. Silva, sobre o tema aponta que

Uma situação delicada, em razão de sua natureza híbrida, é a do cônjuge separado de fato. Afinal, se por um lado não houve a dissolução da sociedade conjugal, por outro inexiste a comunhão de vida entre os cônjuges. A situação legal de cônjuge é suficiente para garantir a presunção de dependência econômica? Ou há necessidade de comprovar o recebimento de alimentos para fazer jus à pensão previdenciária? (SILVA, 2007, p. 3).

Embora haja essa dúvida, em função da determinação imposta pela lei, reforçando o segundo entendimento está o Decreto 3.048/99: “A perda da qualidade de dependente ocorre: I - para o cônjuge, pela separação judicial ou divórcio, enquanto não lhe for assegurada a prestação de alimentos [...]". Nota-se que não é citada a separação de fato como fato que dá ensejo à extinção da dependência. Desse modo, nada impede o juízo, porém, quando convocado, de entender pela permanência do vínculo, se do contrário não puder ser convencido, em função de prova acostada nos autos.

Não bastasse esse impasse interpretativo da situação fática acima referida, com o advento da Súmula 336 do STJ, surgiu mais uma circunstância que amplia a margem para novas interpretações quanto às hipóteses do $\$ 2^{\circ}$, artigo 76 da Lei 8.213/91. A 
referida súmula traz a questão da "necessidade econômica superveniente" prevista apenas para a separação judicial.

Porém, antes que se possa prosseguir com a discussão, torna-se necessário discutir ainda o potencial da separação de fato. É essencial essa discussão, no que se refere à condição civil do indivíduo. E isso é feito no próximo item do presente artigo.

\section{FAMÍlia E VÍNCULO: UMA DISCUSSÃo SOBRE A SEPARAÇÃo DE FATO}

O problema discutido no presente artigo envolve o caráter da Separação de Fato e seu poder de determinar a dissolução de um vínculo legal, bem como interromper a dependência econômica dos indivíduos. Porém, para que se possa estudar essa questão, é preciso discutir o papel da Separação de Fato na sociedade atual. Inicialmente, é necessário referir o tema da família e alguns dos princípios que a envolvem, dentro Ordenamento Jurídico pátrio.

No que se refere ao tema da família, deve-se ter por conta que esta é um importante núcleo para o desenvolvimento do indivíduo. Não apenas pelas relações que se desenvolvem em função da sua existência, mas igualmente pela necessidade de um vínculo essencial, a família deve ser respeitada e protegida. Desse modo, tratou a Constituição Federal de protegê-la, na forma do art. 226. No caput do informado artigo consta que: "Art. 226. A família, base da sociedade, tem especial proteção do Estado." (BRASIL, 2009, p. 70)

Mesmo ante a tal proteção, ferido o animus que mantém a unidade familiar, não pode a mesma persistir. No $\S 6^{\circ}$ do mesmo artigo há uma primeira referência à modificação da condição familiar, na sociedade atual. Pelo texto do parágrafo indica-se que "§ $6 .^{\circ} \mathrm{O}$ casamento civil pode ser dissolvido pelo divórcio, após prévia separação judicial por mais de um ano nos casos expressos em lei, ou comprovada separação de fato por mais de dois anos [grifou-se]. (BRASIL, 2009, p. 70)". Apresenta-se desse modo que a regra formal determina duas opções para o rompimento do vínculo familiar, uma judicial e outra extrajudicial.

A primeira determinação da lei é que a dissolução do vínculo ocorre por força de decisão proferida por autoridade judicial competente. A segunda determinação, ao contrário, defere importância apenas ao adimplemento temporal. Findo, após a Separação de Fato, um prazo superior a dois anos desta, há motivação suficiente para a 
dissolução do vinculo originalmente estabelecido, ou seja, caracterizado está o rompimento do vínculo familiar, pela mera separação física dos indivíduos.

Há que se perceber, porém, que essa última situação cria um problema prático: se a publicidade dos comportamentos determina a aceitação de um fato, não se pode reconhecer a manutenção do vínculo legal, quando há rompimento da convivência. Assim, nota-se que persiste, na Separação de Fato, apenas um registro público de intenções de união matrimonial, mesmo que a base sentimental que originava o vínculo se encontra fragmentada e residual. Nesse sentido é a explicação de Madaleno, uma vez que do vínculo que existia “[...] restou mero assentamento no registro público, e não pode prevalecer sobre a realidade fática de ele ter deixado de existir até mesmo sensorialmente para cada um dos cônjuges, bem como para a comunidade circundante que até os supõe casados com os atuais companheiros.” (MADALENO, s. p.)

O Direito, nesse sentido, encontra fundamento nos fatos. Porém, os fatos que legitimaram o assento registral. E, por conta disso, deve o julgador levar essa questão em consideração. Gontijo destaca, nesse sentido, que é função do Estado a proteção, o que quer dizer

(...) que a Lei deva, sempre, ser interpretada dentro do princípio teleológico insculpido na regra do artigo $5^{\circ}$, da Lei de Introdução ao Código Civil, obrigando o intérprete e o aplicador da lei a buscar os fins sociais a que ela se dirige e às exigências do bem comum. (...) Temos que ter não apenas olhos para enxergar como, com ênfase, coragem para também inovar e adequar nosso posicionamento pessoal àqueles fenômenos sociais emergentes dentro do moderno pensamento jurídico. O ideal seria uma legislação adequada ao seu tempo - para que o Brasil legal bem talhasse o Brasil real - e uma jurisprudência atenta à permanente revisão de precedentes esclerosados pela mutação do modelo social. (GONTIJO, s. d.)

A lógica do Ordenamento Jurídico pátrio incluiu em suas preocupações a Separação de Fato. Ela é instrumento de dissolução do vínculo do casamento. Se essa forma de separação não fosse reconhecida como passível de ensejar rompimento do vínculo registral, ela estaria sendo penalizada legalmente, ao mesmo tempo em que a legislação lhe atribui papel de destaque, na desvinculação de indivíduos. Negar-lhe esse poder de dissolução é uma afronta à lógica da informalidade e da extrajudicialidade, que foi adotada pela legislação sobre o tema.

O direito brasileiro, como filho de suas origens, optou pela consideração de parâmetros datados e datáveis. Porém, isso formaliza um relacionamento que deve 
começar e se reger pelo vínculo da afetividade. Não há como supor que possa haver real sentimento entre seres humanos, quando uma sociedade competitiva e patrimonial aponta como necessário um pensamento que reflete apenas a função econômica dos relacionamentos. Se ocorrida a Separação de Fato, portanto, denota-se que houve motivos suficientes para a sua determinação. Nesse sentido é a visão de Rocha e Baltazar Junior, para quem ela deve ter os mesmos da Separação Judicial, dado seu conteúdo semelhante, no que se refere à determinação de um relacionamento.

O companheiro e a companheira perderão a qualidade de dependente pela cessação da convivência, a não ser que tenha sido reconhecido o direito à percepção de alimentos (RPS, art. 17, II). A cessação do convívio deverá ser tratada nos mesmos moldes do término da relação conjugal. Se ao tempo do óbito a relação havia cessado, sem que o convivente sobrevivente estivesse recebendo pensão alimentícia por conta da cessação do convívio, não há falar em pensão previdenciária. Do contrário, ou seja, se havia pensão alimentícia, ou outro auxílio regular de alimentos, aluguel, etc., estará mantida a qualidade de segurado e haverá o direito à pensão previdenciária, a qual substituirá o ingresso que era feito pelo segurado falecido. (ROCHA; BALTAZAR JÚNIOR, 2006, p. 96)

Se como visto a Separação de Fato autoriza a alteração da situação do casamento torna-se, em decorrência desse fato, necessária a comprovação da dependência econômica para que se possa admitir a concessão do benefício da pensão por morte. Nega essa função aquele julgador que não leva em consideração esta forma de separação, especialmente quando fundamenta sua decisão na força da redação da súmula 336 do STJ. O conteúdo e o sentido legal da referida súmula passa a ser analisada no próximo item do presente artigo.

\section{O SURGIMENTO DO DIREITO A UM BENEFÍCIO: A NECESSIDADE ECONÔMICA SUPERVENIENTE}

As súmulas representam o modo como julgadores de uma determinada instância interpretam a força normativa expressa na lei. Atuam como modelos de análise da realidade e dos valores que devem ser ressaltados, quando se busca fixar os limites de um direito que a legislação concede, bem como de um direito que precisa ser concedido, em função dos princípios que governam o Ordenamento Jurídico. Afinal, como afirma Bobbio (2004), o problema atual não é a definição e sim a efetivação desses direitos. 
No dia 25 de abril de 2007 foi aprovada a Súmula 336 do STJ. Ela possui o seguinte teor: "A mulher que renunciou aos alimentos na separação judicial tem direito à pensão previdenciária por morte do ex-marido, comprovada a necessidade econômica superveniente" (CASTRO, LAZZARI. 2008. p. 587). O projeto da referida súmula baseou-se na vasta jurisprudência do Tribunal que entende que a pensão pode ser intentada após a morte, naqueles casos em que haja necessidade econômica, mesmo estando o laço definido a partir do casamento rompido.

Como dito no item anterior, conforme a Lei 8.213/91, o entendimento quanto à dependência econômica do cônjuge na separação de fato pode oscilar entre ser presumida legalmente ou efetivamente comprovada. O artigo 76, $\S 2^{\circ}$ da Lei 8.213/91, estabelece a forma de comprovação, para três casos: o divórcio, a separação judicial e a separação de fato.

Considerando pela comprovação e não presunção, quanto à separação de fato, esta assim como os outros dois casos, deve anterior a morte do segurado, receber auxílio deste para sua subsistência semelhante ao período da efetiva existência da sociedade conjugal. Esse é o modo para que se possa comprovar a dependência econômica e, com isso, ensejar o recebimento da pensão por morte. Do contrário, não haverá possibilidade futura, de pleitear se a pensão do segurado, se no passado não recebia alimentos. Mesmo que haja efetiva "necessidade econômica superveniente",.

Relembrando então, esse dispositivo, surge certa questão a ser pensada, qual seja, o fato da Súmula 336 do STJ ter compreendido a hipótese da "necessidade econômica superveniente" apenas para a separação judicial, uma vez que está legalmente elencada ao lado de outras duas situações, o divórcio e a separação de fato.

Então, situação oposta e mais favorável é destinada pela súmula apenas àqueles que estão separados judicialmente. Estes, se não assegurados no passado com a pensão alimentícia, podem, no futuro, fazer jus ao benefício pensão por morte, invocando a referida súmula. Ou seja, nesse caso há uma proteção expressa daquele que, surpreendido no futuro, venha necessitar economicamente de auxílio para a sua subsistência.

A Lei 8.213/91 equipara o cônjuge separado judicialmente ao separado de fato. Isso é percebido, pois ambas as situações, estão condicionadas ao recebimento de alimentos para a concessão da pensão por morte. Uma previsão legal em consonância com o Princípio da Igualdade. Tavares (2009) afirma que a Igualdade, enquanto conceito e princípio legalmente inscrito envolvem um ideal específico de justiça, com 
um tratamento desigual aos desiguais, para que se possam ver efetivados. Especialmente considerando-se que tal condição é uma imposição constitucional, segundo o autor.

No mesmo sentido é a ideia expressa por Vechiatti, acerca do mesmo princípio:

Assim, parafraseando Celso Antônio Bandeira de Melo em seu célebre Conteúdo Jurídico do Princípio da Igualdade, a discriminação juridicamente válida é aquela que vise a pessoas indeterminadas e indetermináveis no momento de sua escolha (na elaboração do projeto legislativo), que seja uma decorrência lógico-racional do critério diferenciador erigido e, por fim, que esteja em consonância com os valores constitucionalmente consagrados. (VECHIATTI, 2008, s. p.)

Analisando os dois tipos de separações acima referidas sobre o prisma do Princípio da Igualdade, a "necessidade econômica superveniente" pode vir a alcançar da mesma forma tanto o separado judicialmente, quanto o separado de fato, embora a Súmula 336 não o faça. Pois, concretizado um evento futuro e imprevisto, no momento da sua ocorrência, surge a igualdade de direito. E, comprovada a necessidade, poderá haver a concessão da pensão por morte, nos moldes da súmula in casu, também para o caso da Separação de Fato. Afinal, apenas essa condição pode criar a efetiva igualdade, vez que, como afirma Moraes,

O intérpretelautoridade pública não poderá aplicar as leis e atos normativos aos casos concretos de forma a criar ou aumentar desigualdades arbitrárias. Ressalte-se que, em especial, o Poder Judiciário, no exercício de sua função jurisdicional de dizer o direito ao caso concreto, deverá utilizar os mecanismos constitucionais no sentido de dar uma interpretação única e igualitária às normas jurídicas. [...] (MORAES, 2009, p. 37).

Restringir à existência de alimentos em momento anterior, para possibilitar ao cônjuge separado de fato o recebimento do benefício, estabelece uma equivocada diferenciação, pois isso cria um tratamento desigual para situações que, na prática e na Lei, já foram consideradas estruturalmente semelhantes. O recebimento de pensão alimentícia é circunstância, conforme a já referida súmula, que possibilita o deferimento do benefício para o separado judicialmente. Vê-se ferida aquela igualdade determinada pela Lei 8.213/91, que prevê para ambas as separações os mesmos poderes, dando igual tratamento a estas. Percebe-se, então a "necessidade econômica superveniente", em obediência ao princípio constitucional, deveria abarcar ambas as formas de separação.

Nas palavras de Aurvalle 
Em resumo, a pensão previdenciária devida ao cônjuge separado visa a dar continuidade ao amparo que já vinha sendo outorgado anteriormente à morte. Ao revés, é incompatível ao sistema que, decorrido longo período de ruptura da vida em comum, sem qualquer auxílio material, venha o cônjuge a pleitear a condição de dependente, a partir de um estado de miserabilidade ostentado após a morte do segurado, arrostando igualdade de condições com companheira elou filhos do de cujus presentes no seu passamento. Não seria demasiado dizer que, a valer tal entendimento, estar-se-ia a criar novo objetivo ao matrimônio: o da cobertura previdenciária incondicionada! Ora, gravitando o contrato de casamento em torno do conceito de affectio maritalis, a partir da ruptura da vida em comum, com o esfacelamento de tal núcleo afetivo, a persistência da geração de efeitos jurídicos patrimoniais daí advindos não resiste à interpretação literal, racional, sistemática e teleológica e ao próprio ideal de justiça, chocando-se com os interesses legítimos dos reais dependentes do segurado no momento da morte. (Aurvalle, 2007, s.p.).

Se as separações, judicial e de fato, tivessem um tratamento isonômico, conferido pela Súmula 336 do STJ, a questão da necessidade superveniente ampliaria a possibilidade da concessão da pensão por morte fugindo, porém, da lógica da extinção dos relacionamentos. Nesse caso, estar-se-ia dando crédito, ainda, a um relacionamento que não persiste pela falta de fundamentos.

Em contraponto, a figura da dependência econômica, de certa forma, restringiria essa concessão para ambas. O crédito está para uma necessidade que decorre do compromisso natural e do afeto entre os indivíduos em um relacionamento que se sustenta. Tratando-se, portanto, de forma mais igualitária de fixação de direitos e que respeita o conteúdo da Lei 8.213/91.

\section{CONSIDERAÇÕES FINAIS}

O benefício pensão por morte quanto à separação de fato possui inúmeras controvérsias no âmbito jurídico. Primeiramente, a legislação referente ao assunto, a Lei 8.213/91 dá margem para uma dúbia interpretação, para a concessão do beneficio àqueles que se encontram separados, sem a necessidade da outorga judicial.

A Lei em um primeiro momento, em seu art. 16, inciso I, leva a crer que, a dependência econômica da separação de fato é presumida, pois fazendo uma leitura fria da norma, e remetendo o pensamento à não ocorrência de dissolução da sociedade conjugal, sendo esta apenas na prática e não na esfera jurídica, tal entendimento 
encontra embasamento. Porém, a Separação de Fato evidencia a quebra do vínculo entre os indivíduos, o que quebra igualmente a dependência econômica.

Mais adiante, o artigo $76, \S 2^{\circ}$, traz um requisito a ser demonstrado para a concessão do benefício: o recebimento de pensão alimentícia. Tem-se, assim, em um segundo momento a dependência econômica do separado de fato relativa, pois agora há necessidade de sua comprovação.

Com isso, cabe ao operador do direito estabelecer frente ao caso concreto uma postura que venha a assegurar a melhor aplicabilidade da Lei, uma vez que esta trouxe consigo certa oscilação interpretativa. A principal finalidade deve ser aquela que assegure a pensão para os verdadeiros beneficiários. Portanto, sendo a Lei "imprecisa", a atenção maior cabe às peculiaridades do caso concreto, vindo a se adequar de forma justa a norma à realidade.

A imprevisão é característica inerente ao futuro. Levando em consideração o Princípio da Igualdade, assim como a separação judicial, a separação de fato também deveria usufruir da segurança a posteriori, que foi concedida pela Súmula 336 do STJ apenas a primeira. $\mathrm{O}$ entendimento sumulado fala em renúncia dos alimentos, sendo que no caso da separação de fato, a pensão alimentícia nem sempre é exercida, então como se falar em renúncia nesse caso? Pode-se dizer, diante disso, e forçando um entendimento quanto à realidade, que diante de um longo lapso temporal de separação apenas de corpos, essa renúncia seria tácita.

Constata-se que a exclusividade conferida/sumulada às separações judiciais, através de uma análise extensiva e comprometida com o Princípio da Igualdade, leva ao juízo do cabimento futuro de "necessidade econômica superveniente" por aqueles separados de fato. Sendo na de fato, uma renúncia tácita, a judicial seria expressa. Portanto, não seria adequado a Súmula 336 do STJ restringir a conveniência da "futura oportunidade", até porque, leva a crer que só aqueles que atravessaram uma separação judicial podem sofrer "necessidade futura superveniente", o que é ilógico, considerando-se os revezes que a vida em sociedade pode ter.

Critério mais sábio é, portanto, o da dependência econômica. Especialmente quando se trata do caso da possibilidade de seu reconhecimento em função da presunção para os indivíduos listados no caput do art. 16 da Lei 8.213/91. Ou mesmo da necessidade de sua comprovação, nos casos em que ocorre a Separação de Fato. Não há, pelas peculiaridades da súmula analisada no presente artigo, que se entender por 
igualitário ou respeitando a determinação constitucional aquele julgador que fundamenta sua decisão com base na súmula 336 do STJ.

\section{REFERÊNCIAS BIBLIOGRÁFICAS}

AURVALLE, Luís Alberto d'Azevedo. A pensão por morte e a dependência econômica superveniente. Revista de Doutrina da 4a Região, Porto Alegre, n. 18, jun. 2007. Disponível em: <http://www.revistadoutrina.trf4.jus.br/artigos/Edicao018/Luis_Aurval le.htm>. Acesso em: 10 jan. 2010.

BRASIL. Vade Mecum Saraiva. 7. ed. atual. e ampl.São Paulo: Saraiva 2009.

Lei 8.213, de 24 de jul. de 1991. Dispõe sobre os Planos de Benefícios da Previdência Social e dá outras providências. Disponível em: <http://www.leidireto.com. br/lei-8213.html> Acesso em: 04 jan. 2010.

Decreto 3.048 de 6 de mai. de 1999. Aprova o Regulamento da Previdência Social, e dá outras providências. Disponível em: <http://www3.dataprev.gov.br/SISLEX /paginas/23/1999/3048.htm > Acesso em: 04 jan. 2010.

BOBBIO, Norberto. A era dos direitos. Nova ed. 5. a. reimpress. Rio de Janeiro: Elsevier, 2004.

CASTRO, Carlos Alberto Pereira de; LAZZARI, João Batista. Manual de Direito Previdenciário. 10. ed. Florianópolis: Conceito Editorial, 2008.

CHRISTO, Andriele Gonçalves de. A vida da terceira idade na sociedade de consumo: uma análise do problema da desvinculação de proventos de aposentados e pensionistas ao salário-mínimo. Santa Maria: Faculdade de Direito de Santa Maria, 2009.

GONTIJO, Segismundo. Do regime de bens na separação de fato. Disponível em: <http://www.gontijo-familia.adv.br/sg003.html> Acessado em: 27 mar. 2010. 
MADALENO, Rolf. Regime de bens entre os cônjuges. Direito de Família e o novo Código Civil. In: PEREIRA, Rodrigo da Cunha e DIAS, Maria Berenice. Belo Horizonte: Ed. Del Rey, 2001.

MORAES, Alexandre de. Direito Constitucional. 24. Ed. São Paulo: Atlas, 2009.

PARANÁ. Tribunal Regional Federal $-4^{\mathrm{a}}$ Região. Apelação/Reexame Necessário n. 2009.70.99.001947-5/PR. Publicação: DJ 1/12/2009. Rel. Des. Federal Ricardo Teixeira do Valle Pereira. Disponível em: <http://www.trf4.jus.br/trf4/processos/visuali lizar_documento_gedpro.php?local=trf4\&documento=3128092\&hash=a7f9e933044d7a e21443e61843e4db98>. Acesso em: 04 jan. 2010.

ROCHA, Daniel Machado da; BALTAZAR JUNIOR, José Paulo. Comentários à Lei de Benefícios da Previdência Social. Porto Alegre: Livraria do Advogado, 2006.

SÃO PAULO. Tribunal Regional Federal $-3^{a}$ Região. Apelação Cível $\mathbf{n}^{\circ} 837.918$ 200203990420626/SP. Publicação: DJ 25/05/2005. Rel. Des. Fed. Galvão Miranda Disponível em: <http://www.trf3.jus.br/NXT/Gateway.dll?f=templates\&fn=default.htm \&vid=trf3e:trf3ve>. Acesso em:04 jan. 2010

SILVA, Fábio de Souza. Pensão por morte para ex-cônjuge no Regime Geral de Previdência Social. Disponível em: <http://www.jfrj.jus.br/rev_sjrj/num21/artigos/arti go_05.pdf > Acesso em: 03 jan. 2010.

TAVARES, André Ramos. Curso de Direito Constitucional. 7. ed. São Paulo: Saraiva, 2009.

VECCHIATTI, Paulo Roberto Iotti. Da constitucionalidade e da conveniência da Lei Maria da Penha. Jus Navigandi, Teresina, ano 12, n. 1711, 08 mar. 2008. Disponível em: <http://jus2.uol.com.br/doutrina/texto.asp?id=11030>. Acesso em: 15 abr. 2010. 